\title{
WEAR ANALYSIS OF THE SAPPHIRE WIRE GUIDE IN THE EDM MASHINE
}

\author{
${ }^{1}$ Henryk BĄKOWSKI, ${ }^{1}$ Łukasz ŁOMOZIK, ${ }^{1}$ Damian HADRYŚ, ${ }^{2}$ Zbigniew KRZYSIAK \\ ${ }^{1}$ Silesian University of Technology, Faculty of Transport, Katowice, Poland, EU, \\ henryk.bakowski@polsl.pl, damian.hadrys@polsl.pl \\ 2University of Life Sciences in Lublin, Faculty of Production Engineering, Lublin, Poland, EU \\ zbigniew.krzysiak@up.lublin.pl
}

https://doi.org/10.37904/metal.2019.894

\begin{abstract}
In this paper presented the main problem of wear of sapphire wire guides on EDM machines significantly affects the quality and accuracy of the machined surfaces. Even small geometrical deviations lead to errors in the technological process. This is particularly important in the production of hydraulic motors, where deviations of several dozen micrometres lead to a decrease in the efficiency of the engines. The reduction in torque is caused to leaks due to incorrect technological process and shape errors. Therefore, from this point of view, this type of machining is extremely important from the point of view of the quality of hydraulic motors produced. I this work showed the results of the measurement sapphire wire guide especially the hole in which there is cut wire by means of multi-sensor measuring system to be used in the industrial measuring, inspection and quality control. In simulation research using FEM, determined the distribution and values of stresses and strains in surface layer. The depth of location of stresses in numerical simulation allowed to correlation with metallographic examinations of the wear surface. Depending on the technological parameters (wire speed, wire tension or water pressure), it could be forecast the intensity of wear the sapphire wire guide. This is important to determination intensity of wear and when we should replace guide before we obtain no acceptable roughness surface on industry detail.
\end{abstract}

Keywords: Sapphire wire guide, EDM, wear

\section{INTRODUCTION}

WEDM is one of the types of machining, which is characterized by the production of elements of complex shapes from hard-to-cut materials. The material is removed from the workpiece as a result of electrical erosion between the working electrode (wire) and the workpiece (Figure 1).

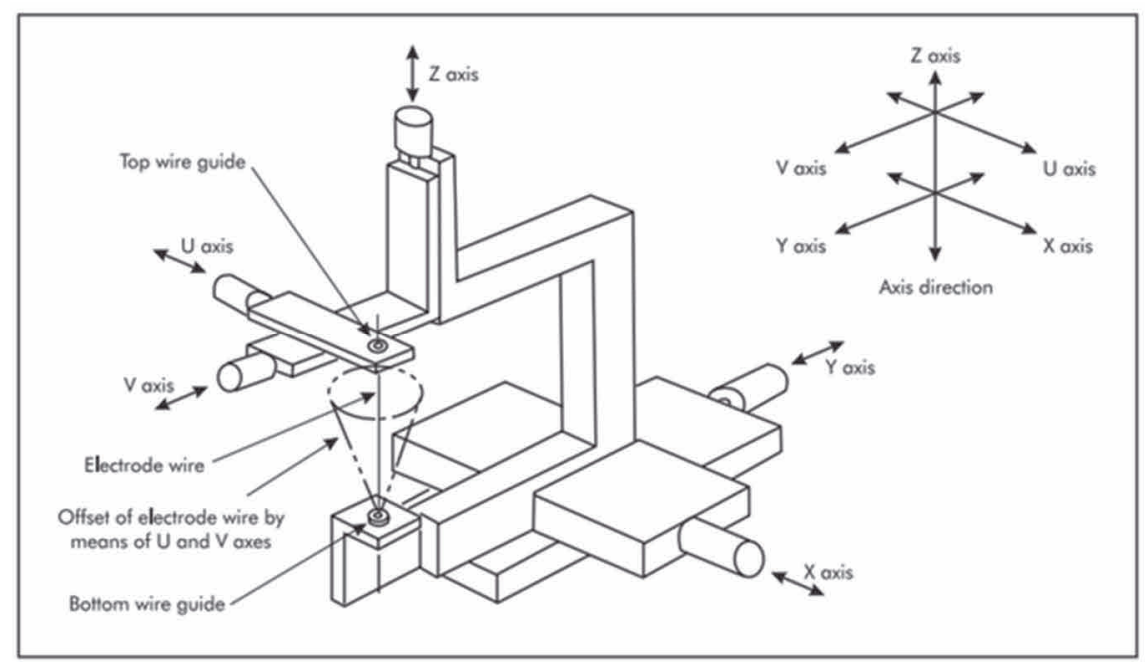

Figure 1 Five-axes wire-cut-machine design [1] 
The condition of the geometrical structure of the surface after EDM is influenced by a number of factors. The shape and depth of individual craters depend mainly on the nature of electrical impulses (processing parameters used), i.e. current intensity, pulse time, time breaks, discharge voltage. Nevertheless, the state of sapphire guides is an important factor, because their wear causes shape and deviation errors, which significantly affects the tolerances and fit of the surfaces to be treated after machining [2].

The phenomenon of material removal is complex and causes electrons to collide with the atoms of the medium leading to their avalanche impact ionization, consequently a narrow plasma channel (Figure 2a). The current flowing through the channel causes melting and evaporation of the workpiece and the electrode (wire) as a result of which depressions called craters (Figure $\mathbf{2 b}$ ) arise. As the electric discharge time increases, the diameter of the plasma channel created around the gas bubble and the ion-filled molten and evaporated metal increases. The end of the generator work cycle, a drop in voltage and current causes implosive closure of the plasma channel and the gas bladder (Figure 2c). The material ejected (blown out by the water pressure) from the craters congeals into the dielectric creating processing products. A part of the material that has not been removed from the crater is freezing on it again (Figure $\mathbf{2 d}$ ). The conditions in the gap stabilize, after which the process is repeated [3].

a)

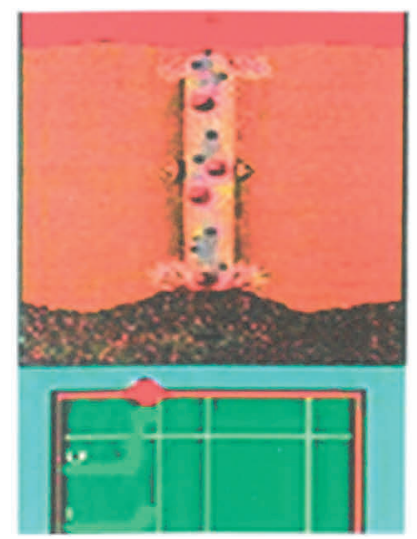

b)

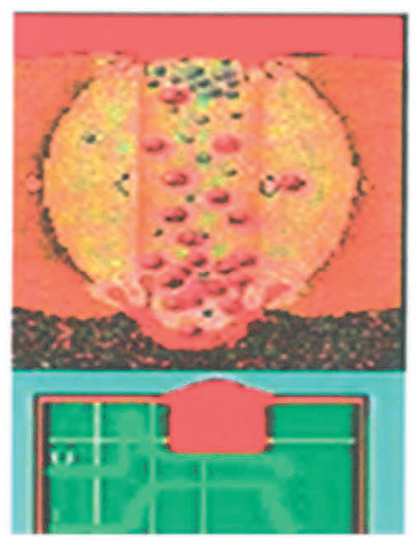

c)

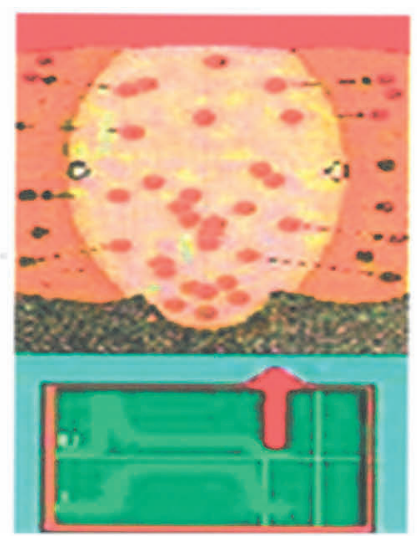

d)

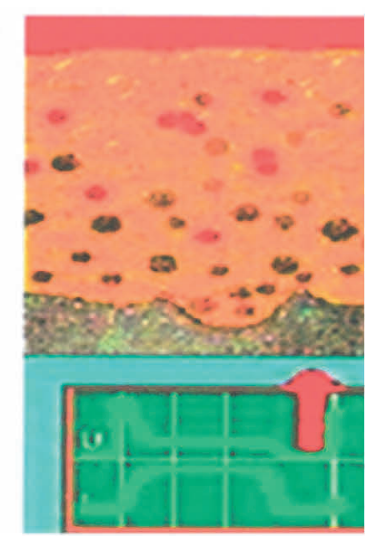

Figure 2 Diagram of the material removal process: a) creating a plasma channel, b) material erosion, c) implosive closure of the plasma channel, d) stabilization of the conditions in the gap [3]

The condition of the surface layer after EDM results mainly from thermal processes and phase transitions through [2]:

- $\quad$ melting and evaporation on the surface of the material,

- creating craters and a new metallographic structure,

- $\quad$ change in the state of stress of the top layer.

However, the occurrence of deviations and shape errors is influenced by the state of sapphire wire guides. Their condition is determined by obtaining nominal dimensions, which, with an accuracy of $0.002 \mathrm{~mm}$, is of great importance for the correct operation of hydraulic motors.

\subsection{Problem}

One of the main problems that have been attempted in this paper is to determine the degree of wear of the sapphire guide used in the wire EDM machine. The metallographic examinations allowed to determine the places most exposed to wear and to assess the permissible wear, after which the workpiece does not meet the manufacturer's requirements. Additionally, simulation tests carried out with the help of MES made it possible to determine the depth of maximum stress and strain. Correlation of the conducted research allowed 
to determine the criterion of acceptable wear, at which it is possible to obtain an acceptable state of the surface layer and stable treatment.

\section{MATERIAL AND EQUIPMENT}

The tests were carried out on a WEDM machine equipped with sapphire wire guides. The tests were conducted under set conditions, i.e. at constant wire feed speed and the same wire tension force. Figure 3 shows the method of measuring sapphire guides on an optical microscope with a measuring accuracy of $0.1 \mu \mathrm{m}$.

a)

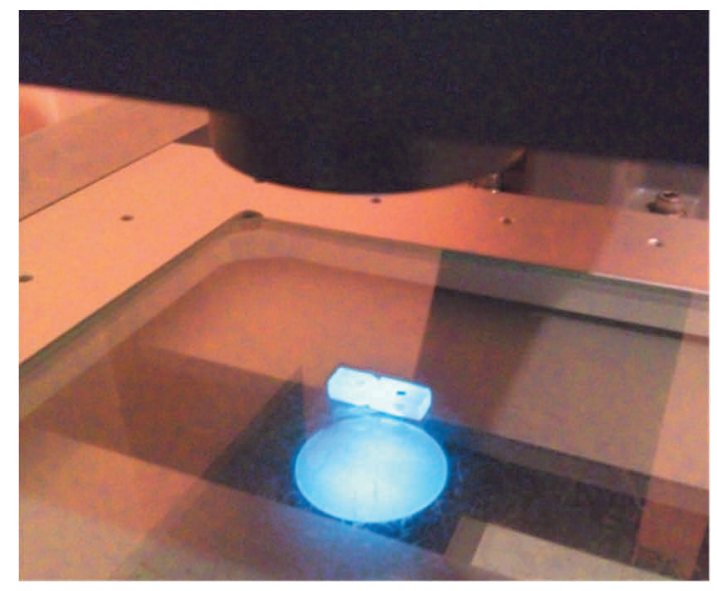

b)

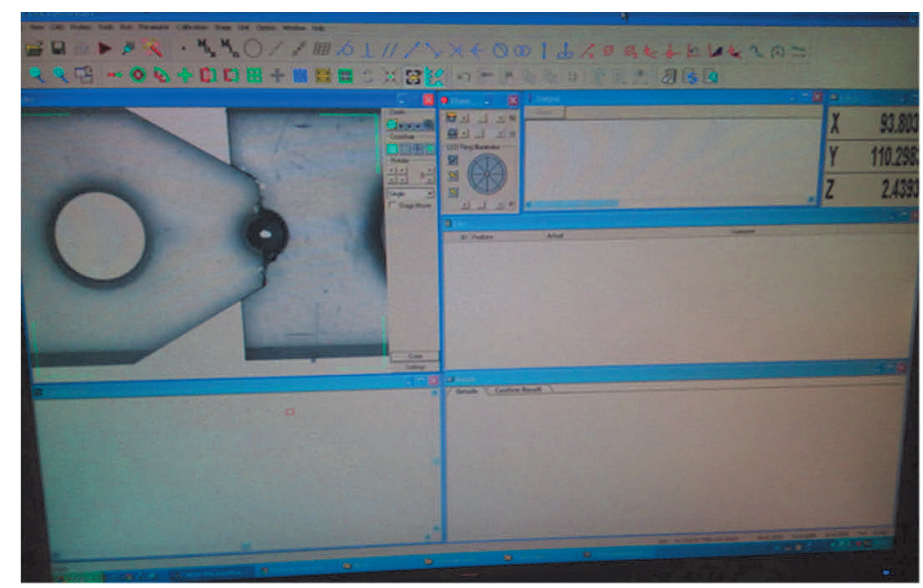

Figure 3 Measurement method: a) on microscope, b) in software

A geometric model was designed for simulation research (Figure 4), which was used to determine the values and distributions of stresses and strains.

a)

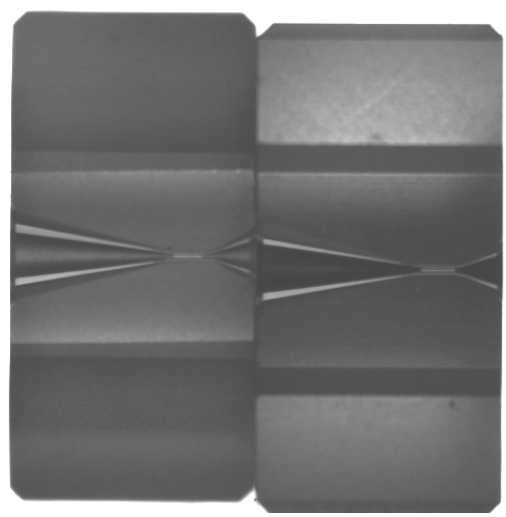

b)

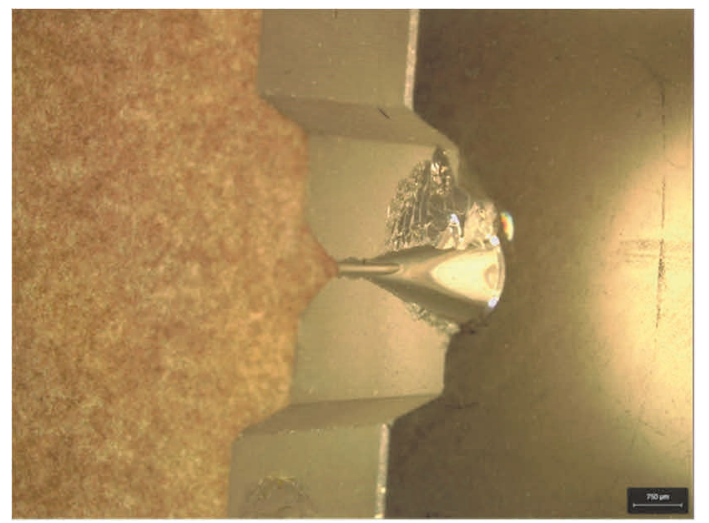

Figure 4 View of the sapphire wire guide: a) real object, b) worn guide

In work [4] authors observed surface with many roughness, and the same sliding contact with kinematic pair.

\subsection{Test procedure}

The numerical calculations were carried out using the Finite Element Method using linear analysis in Autodesk Mechanical Simulation. Figure 5 presents boundary conditions reflecting typical operating conditions occurring in the technological process. 
Authors in work [5] presented special plastic properties with there were in numerical model, especially in wire.

a)

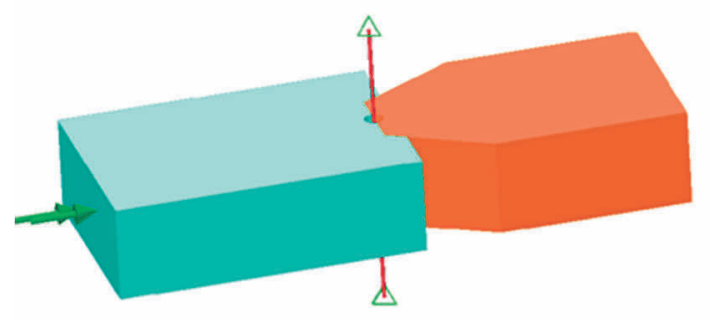

b)

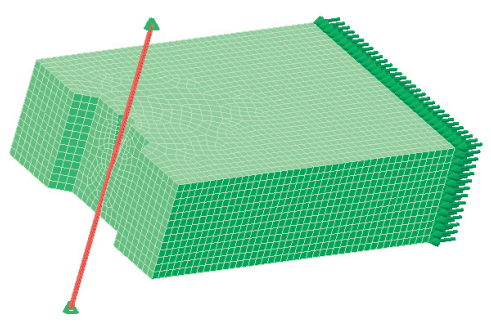

Figure 5 Model 3D of the saphire wire guide (a) and FEM model

Metallographic examinations were performed on an optical microscope and a program for quantitative metallographic analysis (Figure 6).

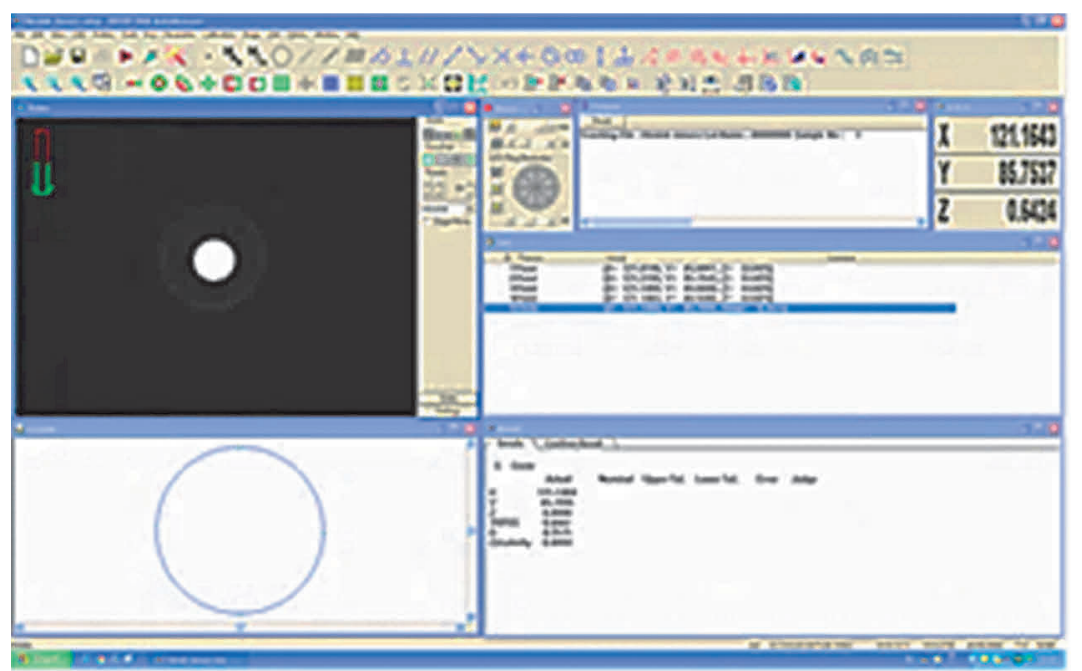

Figure 6 View of software measurement

\section{RESULTS}

In order to determine errors of deviations and shape of openings in which the electrode wire works, the software attached to the optical microscope Inexiv 2520 was used. Measurement was performed and the results obtained are summarized in Table 1. A quantitative metallographic analysis was also performed to determine the stereological features of the analyzed worn sapphire guide holes. The measurement the holes above 300 $\mu \mathrm{m}$ of the diameter is not corrected. The nominal diameter is about $0,21 \mathrm{~mm}$.

Table 1 Statement of the stereological parameters of the holes in saphire wire guide

\begin{tabular}{|c|c|c|}
\hline Geometrical parameters & $\begin{array}{c}\text { Average } \\
(\mu \mathrm{m})\end{array}$ & $\begin{array}{c}\text { Deviation } \\
(\boldsymbol{\mu m})\end{array}$ \\
\hline Diamater & 347.76 & 89.4 \\
\hline Shape indicator & 0.89 & 0.12 \\
\hline Elongation & 1.31 & 0.29 \\
\hline
\end{tabular}


Metallographic examination were presented on Figures 7.

a)

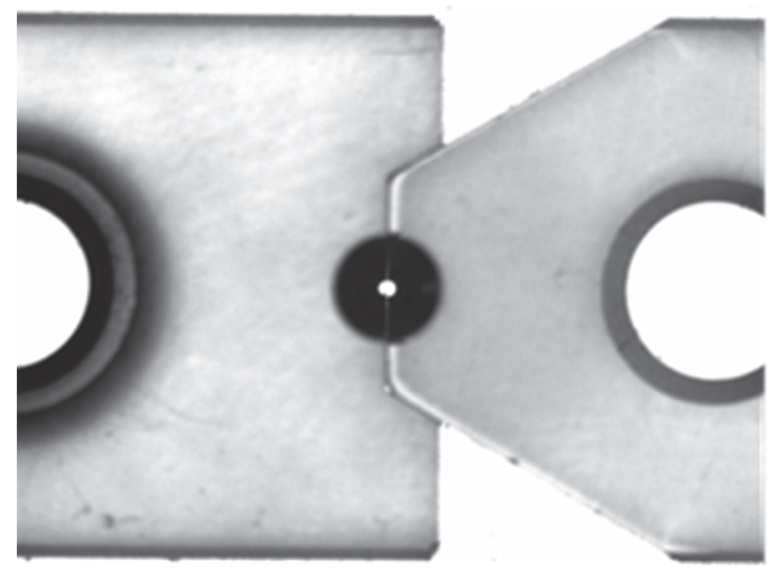

c)

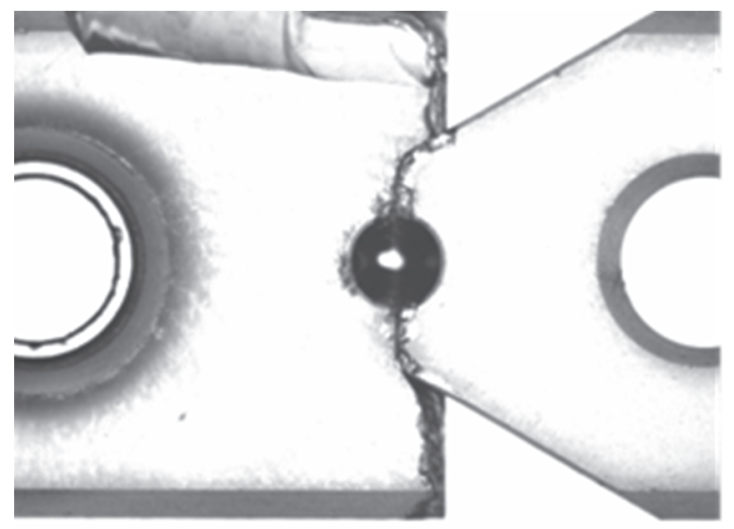

e)

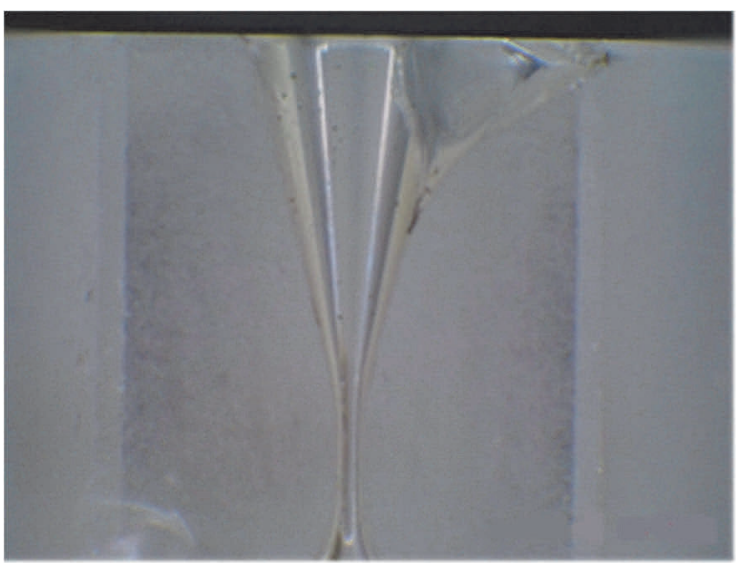

b)

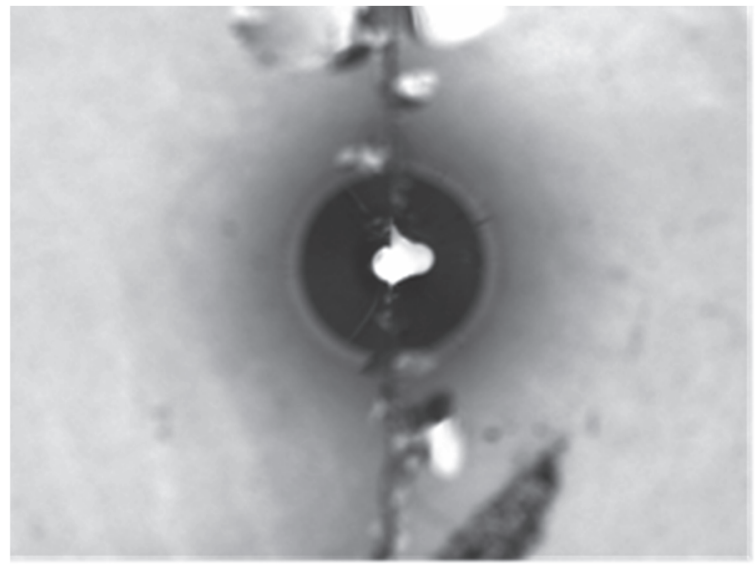

d)

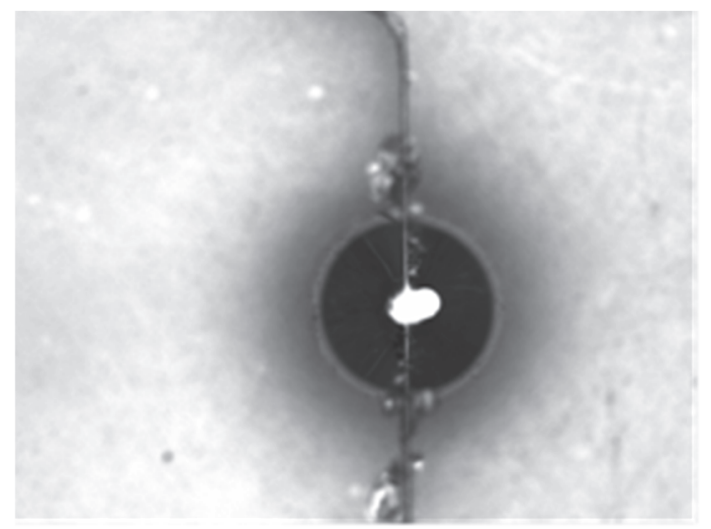

f)

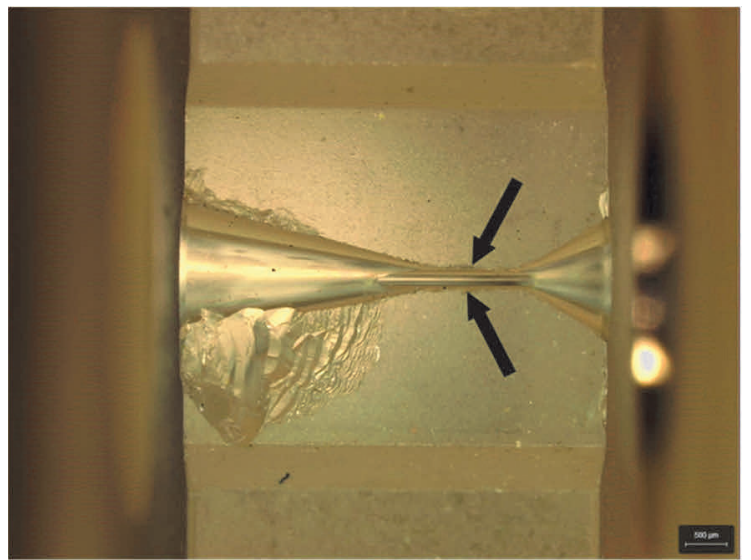

Figure 7 View of the sapphire wire guide: a) non wear guide, b), c), d) worn wire guide, e) part of guide with non acceptable surface roughness

Numerical studies confirm the occurrence of wear (Figure 8) in places observed in metallographic studies (Figure 7f). This indicates the correct selection of boundary conditions. 

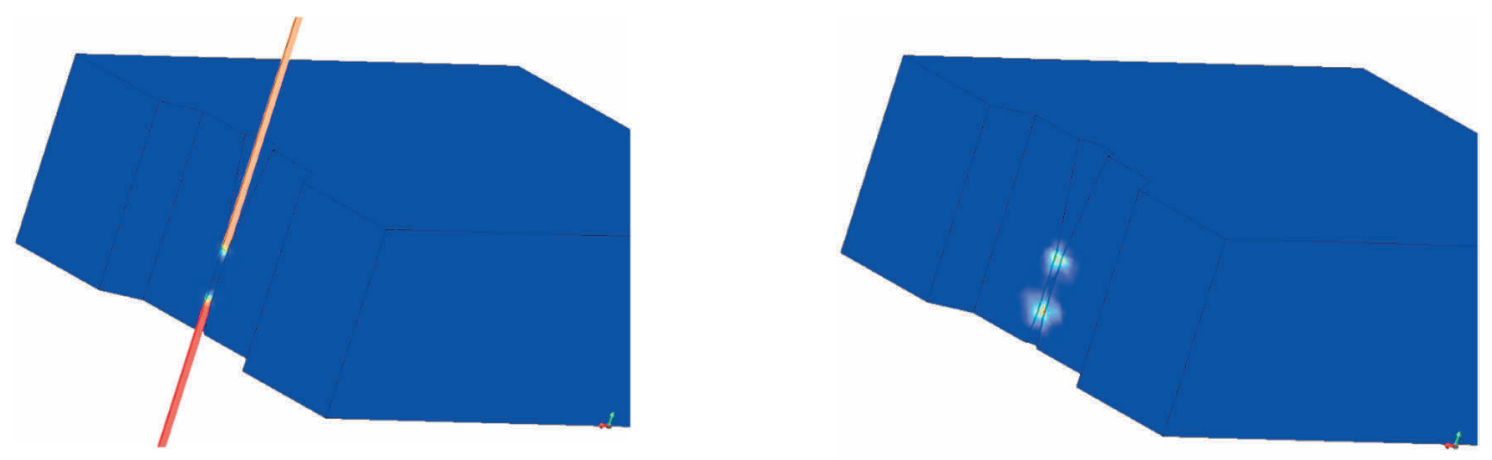

Figure 8 Place of stresses in which wear process appeared

\section{CONCLUSION}

As a result of metallographic and simulation tests, it was found that:

- there is a correlation of the depth of occurrence of damages on the surface of the sapphire guide and the depth of residual maximum stress determined in simulation tests by the finite element method,

- $\quad$ it is possible to determine the degree of wear based on preset technological parameters that will prevent further exploitation,

- the durability of the sapphire guide is influenced by the wire feed speed and the wire tension,

- $\quad$ in the future, conducting laboratory tests based on the experimental design that captures the impact of variable technological parameters will allow forecasting the wear level of the guides and control the geometrical parameters (shape errors and size of deviations) of the processed material.

\section{REFERENCES}

[1] JAMESON E.C. Electrical Discharge Machining: Society of Manufacturing Engineers Dearborn, Michigane: International Standard Book Number: 0-87263-521-X, 2001. p. 342.

[2] ŚWIERCZ A., ŚWIERCZ-ONISZCZUK D. Influence of EDM parameters on the functional properties of the steel with a high thermal conductivity. Mechanik nr 1/2015, pp. 29-34.

[3] DĄBROWSKI L., ŚWIERCZ R. Badania mikrostruktury warstwy wierzchniej po obróbce elektroerozyjnej (EDM). Świat Obrabiarek nr 1-2/2012, pp. 26-30.

[4] Korzekwa, J., Skoneczny, W., Dercz, G., Bara, M. Wear mechanism of Al2O3/WS2 with PEEK/BG plastic. Journal of Tribology 136 (1), art. 011601.

[5] Hadrys D., Wegrzyn T., Piwnik J. lastic properties of fine-grained WMD after micro-jet cooling. Archives of Metallurgy And Materials, Volume: 59, Issue: 3, 2014, pp. 919-923, DOI: 10.2478/amm-2014-0155. 